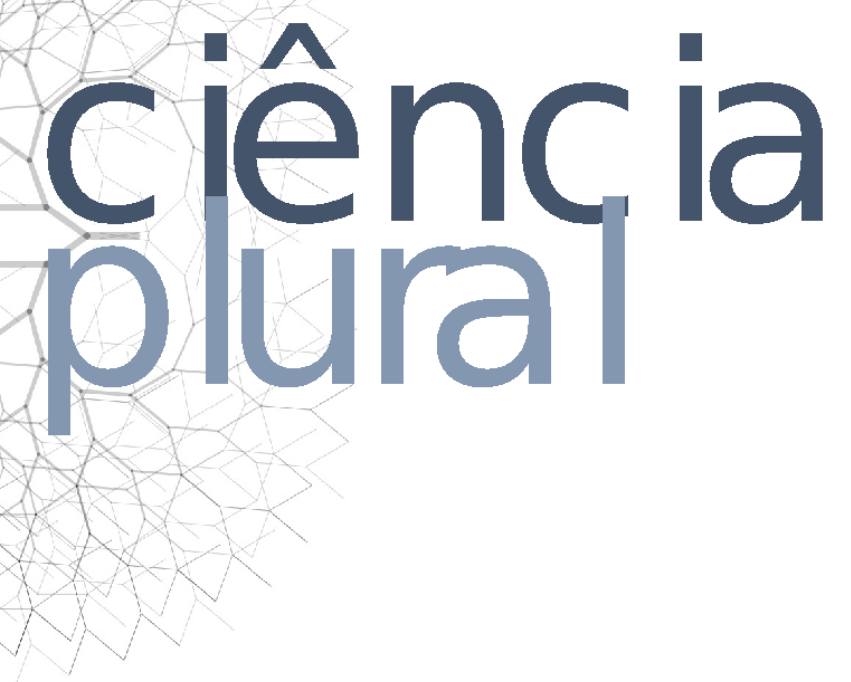

\title{
INFLUÊNCIA DA TÉCNICA DE PREPARO SOBRE O CONTORNO CERVICAL DOS LAMINADOS CERÂMICOS: RELATO DE CASO
}

Influence of the preparation technique on the cervical contour of ceramic laminates: a case report

Influencia de la técnica de preparación en el contorno cervical de los laminados cerámicos: reporte del caso

Lívia Luiza Carvalho da Silva • Graduada em Odontologia • Centro Universitário Tiradentes• E-mail: livialuiza15@gmail.com

Douglas Ferreira da Silva • Graduando em Odontologia • Centro Universitário Tiradentes • E-mail: douglasferreira70@hotmail.com

Raphaela Farias Rodrigues • Professora Adjunta • Universidade Federal de Alagoas - E-mail: raphaelarodriguesf@gmail.com

Fernanda Carvalho de Rezende • Professora Titular • Centro Universitário Tiradentes • E-mail: fecarvalhorezende@hotmail.com

Autora correspondente:

Lívia Luiza Carvalho da Silva • E-mail: livialuiza15@gmail.com 


\section{RESUMO}

Introdução: Devido à crescente demanda estética, a odontologia restauradora se renova na intenção de alcançar melhores resultados na harmonia do sorriso. Entretanto, a atenção deve voltar-se também aos tecidos periodontais, visto que há uma integração entre material restaurador e os tecidos. Objetivo: Descrever e discutir as etapas clínicas para a confecção de laminados cerâmicos, atentando-se a preparos minimamente invasivos, contorno cervical e fatores que podem intervir na longevidade do procedimento. Relato de caso: Paciente do sexo masculino, 28 anos de idade, compareceu a Associação Brasileira de Odontologia, seção de Alagoas, relatando insatisfação em relação ao tamanho dos seus dentes. Os arcos superior e inferior foram moldados para a obtenção dos modelos de estudo e enceramento diagnóstico. Ao início do tratamento foi orientado ao paciente clareamento dental pela técnica combinada. O preparo dos dentes foi guiado por uma matriz de silicone, sendo estes uniformes e conservadores, seguido de moldagem, fase laboratorial e cimentação final. Finalizado o caso foi realizado o ajuste oclusal solicitando ao paciente que realizasse movimentos de lateralidade e protrusão. Conclusões: A técnica do preparo influência na longevidade dos laminados cerâmicos, por relacioanar-se à adesão e a saúde periodontal. O preparo deve ser mínino e limitado ao esmalte dental sempre que possível, determinando assim um maior e melhor prognóstico.

Palavras-Chave: Cerâmica; Preparo Prostodôntico do Dente; Periodonto.

\section{ABSTRACT}

Introduction: Due to the growing aesthetic demand, restorative dentistry is renewed to achieve better results in smile harmony. However, attention should also be turned to periodontal tissues since there is an integration between restorative material and tissues. Objective: To describe and discuss the clinical steps for the manufacture of laminate veneers, paying attention to minimally invasive preparations, cervical contour, and factors that can intervene in the procedure's longevity. Case report: A 28year-old male patient attended the Brazilian Dental Association, the Alagoas section, reporting dissatisfaction with his teeth' size. The upper and lower arches were molded to obtain the study and diagnostic waxing models. At the beginning of treatment, the patient was instructed by the combined technique. After the case, the occlusal adjustment was performed, asking the patient to perform laterality and protrusion movements. Conclusions: The preparation technique influences the longevity of laminate veneers due to adherence and periodontal health. The preparation should be minimal and limited to dental enamel whenever possible, thus determining a higher and better prognosis.

rds: Ceramics; Prostodontic Preparation of the Tooth; Periodontium. 


\section{RESUMEN}

Introducción: Debido a la creciente demanda estética, la odontología restauradora se renueva para lograr mejores resultados en la armonía de la sonrisa. Sin embargo, también se debe prestar atención a los tejidos periodontales ya que existe una integración entre el material restaurador y los tejidos. Objetivo: Describir y discutir los pasos clínicos para la confección de carillas laminares, prestando atención a las preparaciones mínimamente invasivas, al contorno cervical y a los factores que pueden intervenir en la longevidad del procedimiento. Reporte del caso: Un paciente masculino de 28 años asistió a la Asociación Dental Brasileña, sección de Alagoas, reportando insatisfacción con el tamaño de sus dientes. Los arcos superior e inferior fueron moldeados para obtener los modelos de depilación de estudio y diagnóstico. Al comienzo del tratamiento, el paciente fue instruido por la técnica combinada. La preparación de los dientes fue guiada por una matriz de silicona, siendo estas uniformes y conservadoras, seguidas de moldeo, fase de laboratorio y cementación final. Después del caso, se realizó el ajuste oclusal, pidiendo al paciente que realizara movimientos de lateralidad y protuberancia. Conclusiones: La técnica de preparación influye en la longevidad de los laminados cerámicos, debido a la adherencia y la salud periodontal. La preparación debe ser mínima y limitada al esmalte dental siempre que sea posible, determinando así un pronóstico más alto y mejor.

Palabras clave: Cerámica; Preparación prosodóntica del diente; Periodonto. 


\section{Introdução}

Os laminados cerâmicos são definidos pelo recobrimento da face vestibular do esmalte dentário por uma fina lâmina cerâmica ${ }^{1}$, podendo ser classificados em facetas e lentes de contato ${ }^{2}$. Sua composição pode variar entre cerâmicas reforçadas por leucita, dissilicato de lítio e porcelana feldspática ${ }^{3}$.

De maneira geral, os laminados cerâmicos são indicados para correções de forma, posição ou alterações de cor dental ${ }^{4}$, tendo como principais vantagens excelente estética, durabilidade e biocompatibilidade ${ }^{5}$. Por outro lado, o tratamento com laminados envolve técnicas mais complexas, por contemplar um minucioso protocolo clinico, além de necessitar de treinamento prévio ${ }^{6}$.

De acordo com Morimoto et al., (2016), as lentes de contato atraem atenção por obter uma forma laminada ultrafina, com espessura entre $0,3 \mathrm{~mm}$ a $0,5 \mathrm{~mm}^{7}$, sendo indicadas para aumento da borda incisal, maior volume vestibular, fraturas incisais, restabelecimento de guia canina, restabelecimento da morfologia de dentes conóides e fechamento de diastemas.

O preparo do dente para restauração com lentes de contato pode ser realizado com ou sem desgaste, os quais podem influenciar no contorno cervical da restauração. Assim, ao realizar esses procedimentos, a atenção deve voltar-se também ao periodonto, visto que, o êxito do tratamento não é medido apenas no ato da cimentação, e sim ao longo do tempo por haver uma íntima relação entre a área cervical e os tecidos periodontais, dependendo da sua saúde e estabilidade ${ }^{8}$. Logo, o presente artigo tem como objetivo descrever e discutir as etapas clínicas para a confecção de laminados cerâmicos, atentando-se à preparos minimamente invasivos, contorno cervical e fatores que podem intervir na longevidade do procedimento.

\section{to de caso}

Paciente do sexo masculino, 28 anos de idade, compareceu a Associação Brasileira de Odontologia - ABO, seção de Alagoas, relatando insatisfação em relação 
ao tamanho dos seus dentes. Na primeira consulta foi realizado: anamnese, exame clínico e radiográfico, juntamente com protocolo fotográfico e modelos de estudo para auxiliar no planejamento.

Os arcos superior e inferior foram moldados com alginato (Hydrogum, Zhermack, Itália) para a obtenção dos modelos de estudo e enceramento. O modelo encerado foi duplicado com silicona de condensação obtendo-se uma cópia em negativo para confecção de guias de silicone (Figura 1).

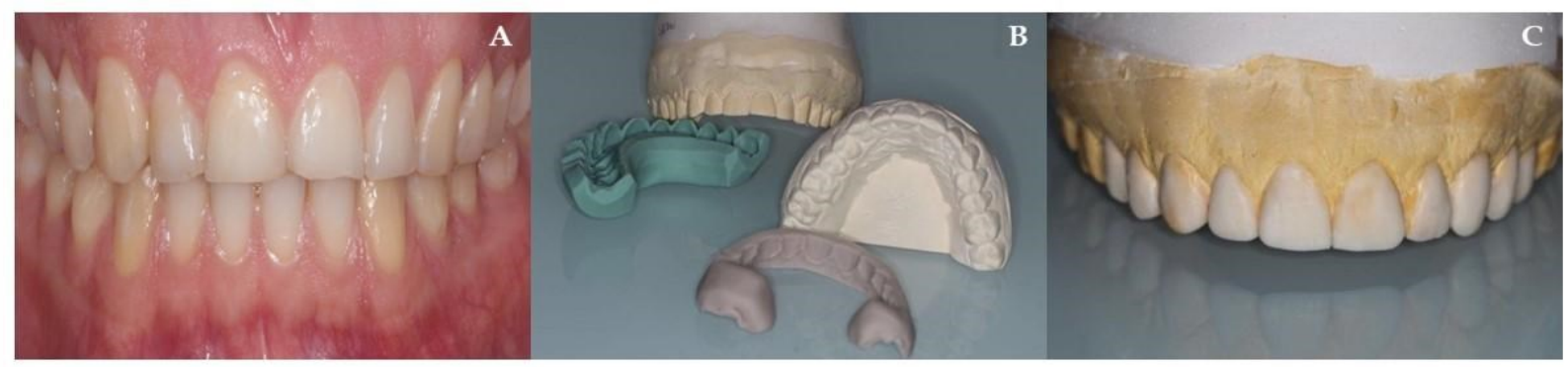

Figura 1. Aspecto inicial do sorriso e moldagem de estudo. (1A- Fotografia evidenciando o aspecto inicial do sorriso. 1B- Guias de silicone obtidas sobre o modelo de enceramento diagnóstico. 1C- Modelo encerado). Maceió-AL, 2020.

O ensaio restaurador (mock-up) foi executado com resina bis-acrílica (Protemp, cor A1, 3M, EUA), observando o formato dos dentes propostos pelo planejamento (Figura 2A). Testes de protrusão e lateralidade foram realizados, visto que uma nova guia seria estabelecida.

Ao início do tratamento foi orientado ao paciente clareamento dental pela técnica combinada. Foram realizadas 2 sessões de clareamento dental de consultório Total Blanc (Nova DFL, Rio de Janeiro, RJ, Brasil), associado com a técnica caseira, utilizando o gel clareador Clariant 16\% (Figura 2B e 2C).

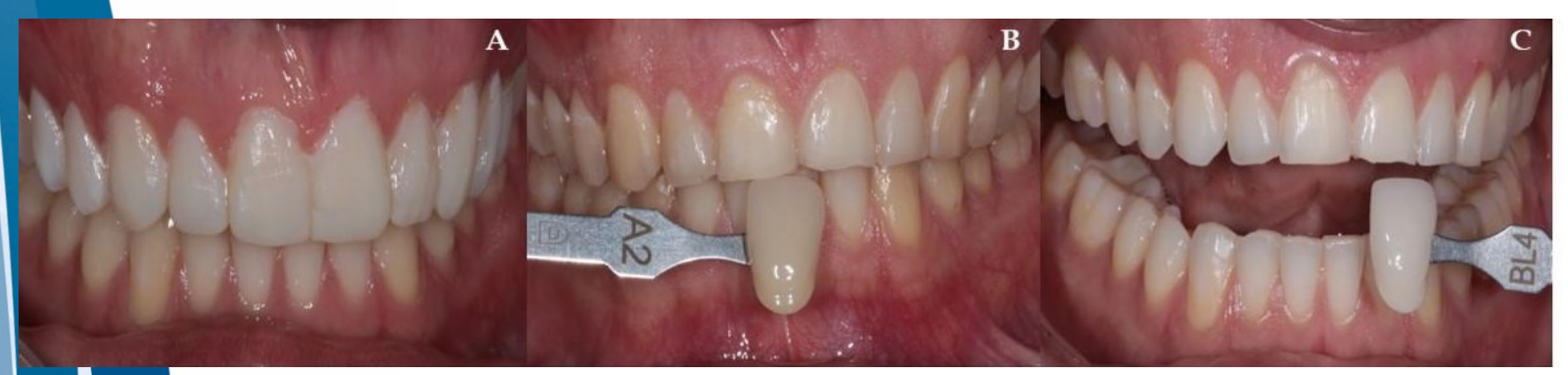


Figura 2. Ensaio restaurador (mock-up) e clareamento dental. (2A- Mock-up. 2BSeleção de cor antes do clareamento dental. 2C- Seleção de cor após clareamento dental). Maceió-AL, 2020.

Após a finalização da etapa clareadora o paciente retornou aos atendimentos para que desse início a etapa restauradora. Para preparar os elementos dentais foram utilizadas pontas diamantadas (2135 KG Sorensen) acopladas a motor de alta rotação. Uma matriz de silicone, confeccionada com silicone de condensação (Zetababor, Zhermack, Itália) foi utilizada com o objetivo de orientar os desgastes (Figura 3A), o que possibilitou uma espessura uniforme e preparos conservadores (Figura 3B). A moldagem dos preparos foi realizada utilizando silicona de adição (Express XT, 3M, USA) através da técnica da dupla mistura e enviada ao laboratório para a confecção dos laminados (Figura 3C).

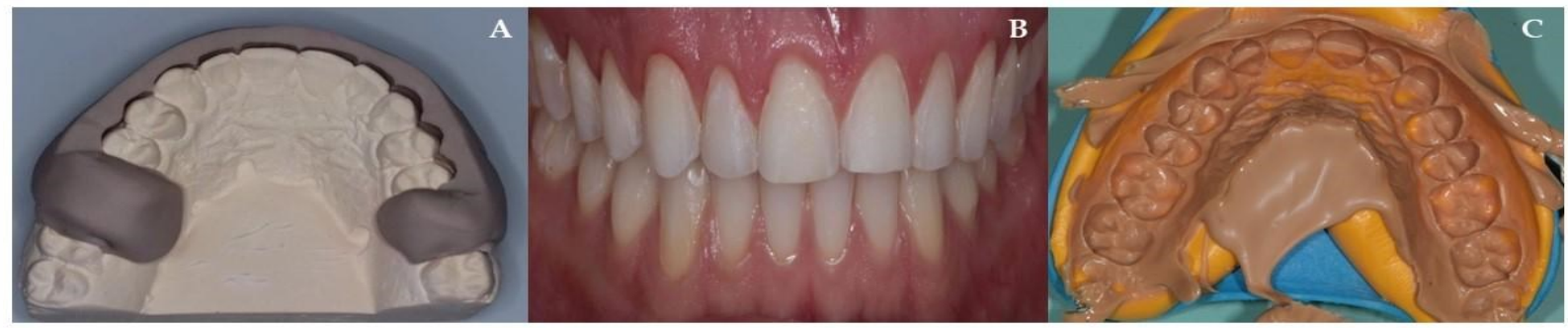

Figura 3. Etapas contemplando o pré e pós preparo dental. (3A- Matriz de silicone para orientar os preparos. 3B- Elementos após a etapa de preparo. 3C- Moldagem dos preparos com silicona de adição). Maceió-AL, 2020.

Foi realizada a análise de cor dos substratos dentais com o auxilio da escala VITA e enviadas juntamente com fotografias intraorais ao laboratório. Após a confecção das peças cerâmicas pelo protético, mediu-se a espessura dos laminados, onde estes mediam entre 0,5 a $0,6 \mathrm{~mm}$ (Figura $4 \mathrm{~A}$ e 4B). Logo, foi realizada a prova seca e o teste com as pastas de prova (Try-in) no paciente. 


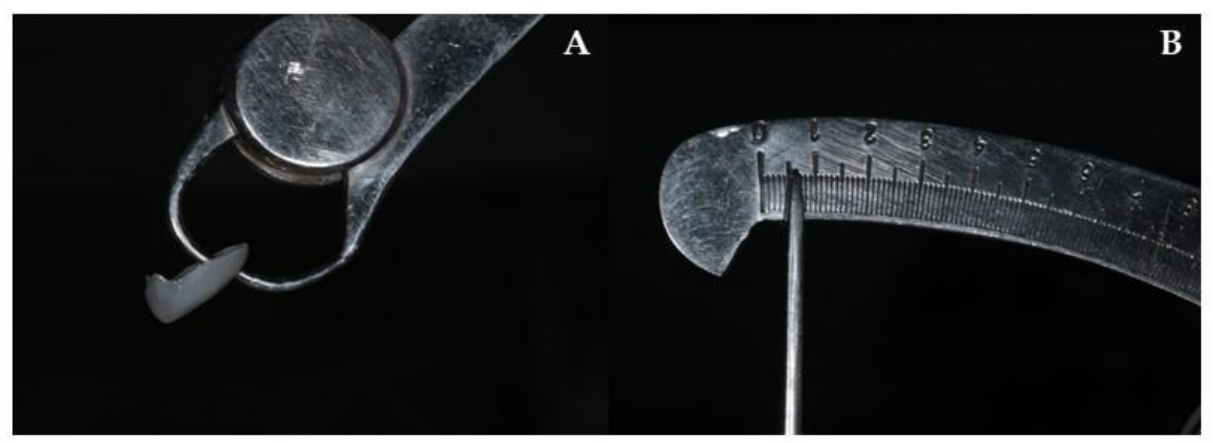

Figura 4. Mensuração das peças através de especímetro. (4A- Medição da espessura. 4B- Especímetro marcando de 0,5 a 0,6mm). Maceió-AL, 2020.

A cimentação definitiva dos laminados cerâmicos de dissilicato de lítio (E-max) iniciou-se com o condicionamento da superfície interna das peças com ácido fluorídrico a 10\% (Condac Porcelana, FGM) durante 20 segundos. O ácido foi removido por meio da lavagem com água e as peças secas com jato de ar. Após a aplicação do ácido fluorídrico, foi aplicado ácido fosfórico a 37\% no interior das peças durante 15 segundos para limpeza das mesmas, seguido de sua remoção com água. Foram aplicadas duas camadas de silano (Silano Prosil, FGM) e aguardou-se 60 segundos para evaporação do solvente. O agente adesivo convencional Adper Single Bond 2 (3M Dental Products Division, St. Paul, Minessota, Estados Unidos) foi aplicado posteriormente seguido de um jato de ar, para também evaporação do seu solvente.

Para o preparo do substrato, o mesmo foi condicionado com ácido fosfórico $37 \%$ durante 30 segundos, seguido da sua remoção com jatos de água e a superfície foi seca com jatos de ar, por se tratar de esmalte. $\mathrm{O}$ agente adesivo foi aplicado com aplicador descartável (microbrush) por todo o substrato e fotopolimerizado por 20 segundos. Para a cimentação das peças foi utilizado cimento resinoso fotopolimerizável (RelyX Venner TR, 3M, USA). A polimerização inicial foi feita durante 10 segundos (Figura 8). Os excessos foram removidos com fio dental e pontas descartáveis (Cavibrush, FGM, Joinville, SC). Por fim, a polimerização final foi realizada por 1 minuto em cada face. Finalizado o caso, foi realizado o ajuste oclusal solicitando ao paciente que 
realizasse movimentos de lateralidade e protrusão. $O$ resultado final pode ser observado na figura 5.

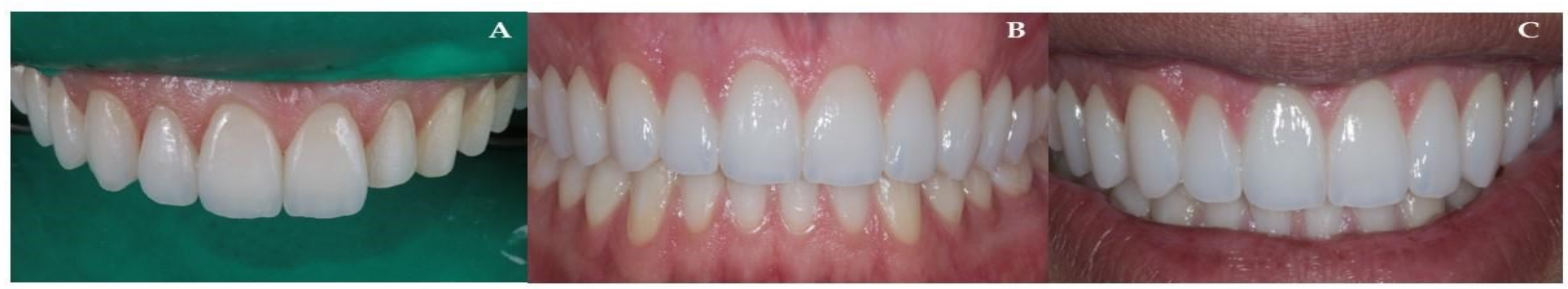

Figura 5. Resultado final durante e após a cimentação dos laminados cerâmicos. (5ADurante a cimentação. 5B- Aspescto final por uma fotografia intraoral. 5C- Aspescto final por uma fotografia extraoral). Maceió-AL, 2020.

\section{Discussão}

Ao comparar a longevidade dos laminados cerâmicos em relação as resinas compostas, Gresnigt et al, (2018) observou que a longo prazo, as resinas compostas apresentam rugosidade superficial, degradação marginal e falhas na adesão, sendo necessário a manutenção periódica das restaurações 9 .

As cerâmicas odontológicas oferecem melhorias substanciais no comportamento óptico, estabilidade de cor, formato, e propriedades físicas e mecânicas superiores em relação às resinas compostas. As melhorias no coeficiente de expansão térmica, no tamanho e na distribuição de partículas levaram as restaurações cerâmicas a obter maior resistência à fratura e microinfiltração, proporcionando um melhor prognóstico ${ }^{10}$.

A associação entre laminados cerâmicos e periodonto é citada como sinônimo de cautela, devido a maior preferência de preparo subgengival por razões estéticas, e as possíveis reações negativas causadas pelo sobrecontorno ${ }^{11}$ que pode ser mais frequente em restaurações sem desgaste. Para evitar esse inconveniente, nesse relato de caso foram realizados desgastes dentários mínimos, 0,5 a 0,6 mm, para garantir adaptação do laminado cerâmico sem comprometer a saúde periodontal.

No estudo de Arif et al., (2019)12 42\% dos laminados cerâmicos avaliados taram inflamação gengival moderada associada ao sangramento à sondagem. 
Tal número associa-se à íntima aproximação da peça cerâmica ao periodonto. No presente caso, os preparos foram realizados através de guias de silicone, tendo assim a máxima conservação da estrutura dentária e menor índice de danos periodontais.

Para sanar os possíveis problemas, a técnica de preparo dental deve, quando empregada subgengivalmente, prezar pela manutenção do espaço biológico, extendendo-se entre $0,5 \mathrm{~mm}$ a $1,0 \mathrm{~mm}^{13}$. Porém, esses valores não corroboram com o estudo de Kois (1994), onde o autor cita que términos localizados 1,0mm subgengivalmente podem ocasionar inflamação exarcebada, aumento de sangramento à sondagem e perda de inserção ${ }^{14}$. Assim, percebe-se que quanto menor a extensão do preparo sobre os tecidos, menor a chance de complicações iatrogênicas.

Edelhoff e Sorensen (2002) relatam a técnica de preparo confeccionado por brocas calibradas, que visam reduzir a estrutura dental de maneira uniforme. Logo, dessa forma, a probabilidade de um preparo agressivo torna-se maior, visto que a técnica não considera aspectos anatômicos e a preservação do esmalte como regra. Como utilizado no presente caso, a técnica de preparo guiada por matriz de silicone propicia maior previsibilidade e conservação ${ }^{15}$, por basear-se em modelos prévios e na anatomia futura da restauração ${ }^{16}$.

Além disso, nota-se que laminados cerâmicos cimentados sobre a estrutura da dentina apresentam sobrevida menor, justificado pela biodegradação da interface cerâmica-dentina ${ }^{17}$. Logo, o preparo deve ficar completamente em esmalte, sempre que possível, e deve ser minimamente invasivo para evitar o sobrecontorno na face do elemento dental, gerando uma aparência saudável e o volume ideal ${ }^{18}$.

Morita et al., (2016) avaliou em seu estudo que fatores clínicos como a descoloração dentária e o apinhamento podem exigir modificação da técnica de preparo, levando a uma maior redução do esmalte ${ }^{18}$.

Ainda, fraturas da peça podem ocorrer, caso a superfície do substrato dental não seja preparada o suficiente para criar espaço para alojar o laminado, assim como preparos profundos que expõem a dentina aumentam o risco de microinfiltração e fraturas adesivas, além de cárie secundária e sensibilidade pós-operatória ${ }^{19}$. Dessa 
forma, deve-se planejar meticulosamente o caso, realizar uma preparação guiada e preservar o esmalte sempre que possível.

Logo, percebe-se que o preparo para laminados cerâmicos deve prezar pelo mínimo desgaste, proporcionando a adesão ideal da peça, diminuindo as chances de retenção de biofilme em suas interfaces favorecendo higienização adequada, preservando o espaço biológico e consequentemente a saúde periodontal ${ }^{20}$. Então, há um compilado de etapas, necessários para o êxito do tratamento.

\section{Conclusões}

- A técnica do preparo influência na longevidade dos laminados cerâmicos por estar relacionado à adesão e a saúde periodontal;

- $\quad$ O preparo deve ser mínino e limitado ao esmalte dental, sempre que possível;

- $\quad$ Preparos mais profundos aumentam o risco de microinfiltração, fraturas adesivas, cárie secundária e sensibilidade pós-operatória;

- A utilização de laminados cerâmicos sem preparo sobre a estrutura dental pode ocasionar sobrecontorno cervical e como consequência danos periodontais.

\section{Referências}

1. Kina, S., \& Invisível, B. A. restaurações estéticas cerâmicas. Maringá: Dental Press Estét. 2007.

2. Magne, P., \& Belser, U. Restaurações adesivas de porcelana na dentição anterior: uma abordagem biomimétrica. Quintessence. 2003.

3. Radz, G. M. Minimum thickness anterior porcelain restorations. Dental Clinics of North America. 2011; 55(2), 353-370.

4. Fons Font, A., Solá Ruiz, M. F., Granell Ruiz, M., Labaig Rueda, C., \& Martínez González, A. Choice of ceramic for use in treatments with porcelain laminate veneers. 2006.

5. Fradeani, M., Redemagni, M., \& Corrado, M. Porcelain laminate veneers: 6-to 2-year clinical evaluation--a retrospective study. International journal of periodontics \& restorative dentistry. 2005; 25(1). 
6. Baratieri, L. N. et al. Facetas de porcelana in Odontologia restauradora: fundamentos e possibilidades. 4. ed. São Paulo: Ed. Santos, 2015. p. 595-615.

7. Morimoto S, Albanesi RB, Sesma N, Agra CM, Braga MM. Main Clinical Outcomes of Feldspathic Porcelain and Glass-Ceramic Laminate Veneers: A Systematic Review and Meta-Analysis of Survival and Complication Rates. Int J Prosthodont. 2016; 29 (1): 38-49.

8. Hong N, Yang H, Li J, Wu S, Li Y. Effect of Preparation Designs on the Prognosis of Porcelain Laminate Veneers: A Systematic Review and Meta-Analysis. Oper Dent. 2017; 42 (6): 197-213.

9. Gresnigt MMM, Cune MS, Jansen K, van der Made SAM, Özcan M. Randomized clinical trial on indirect resin composite and ceramic laminate veneers: Up to 10-year findings. J Dent. 2019; 86:102-109.

10. Chee, H. T., Wan Bakar, W. Z., Ghani, Z. A., \& Amaechi, B. T. Comparison of composite resin and porcelain inlays for restoration of noncarious cervical lesions: An in vitro study. Dental research journal. 2018, 15 (3): 215-219.

11. Friedman M. Multiple potential of etched porcelain laminate veneers. J Am Dent Assoc. 1987; Spec No:83E-87E.

12. Arif R, Dennison JB, Garcia D, Yaman P. Gingival Health of Porcelain Laminate Veneered Teeth: A Retrospective Assessment. Oper Dent. 2019;44(5):452-458.

13. Nevins, M. \& Skurow H. M. The intracrevicular restorative margin, the biologic width, and the maintenance of the gingival margin. International Journal of Periodontics and Restorative Dentistry. 1984; 3, 31-49.

14. Kois JC. Altering gingival levels: The restorative connection, Part I: Biologic variables. J. Esthet Dent 1994; 6:3-9.

15. Edelhoff D, Sorensen JA. Tooth structure removal associated with various preparation designs for anterior teeth. J Prosthet Dent. 2002; 87(5):503-509.

16. Magne P, Belser UC. Novel porcelain laminate preparation approach driven by a diagnostic mock-up. J Esthet Restor Dent. 2004;16(1):7- 16.

17. Blunck U, Fischer S, Hajtó J, Frei S, Frankenberger R. Ceramic laminate veneers: effect of preparation design and ceramic thickness on fracture resistance and marginal quality in vitro. Clin Oral Investig. 2020; 24 (8): 2745-2754.

Morita RK, Hayashida MF, Pupo YM, Berger G, Reggiani RD, Betiol EA. Minimally Invasive Laminate Veneers: Clinical Aspects in Treatment Planning d Cementation Procedures. Case Rep Dent. 2016; 2016: 1839793. 
19. Alavi AA, Behroozi Z, Nik Eghbal F. The Shear Bond Strength of Porcelain Laminate to Prepared and Unprepared Anterior Teeth. J Dent (Shiraz). 2017; 18 (1): 50-55.

20. Tsubota K. Ten-year clinical observation of a porcelain laminate veneer seated with biological tissue adaptation (BTA) technique. J Oral Sci. 2017; 59 (2): 311314. 